\title{
Southern Hemisphere Circulation anomalies and impacts over Subtropical South America due to different EI Niño flavors
}

\author{
Verónica Martín - Gómez ${ }^{1 *}$, Marcelo Barreiro ${ }^{1}$, Teresa Losada ${ }^{2}$, Belén Rodríguez - Fonseca $^{2}$ \\ ${ }^{1}$ Departamento de Ciencias de la Atmósfera, Universidad de la República (Uruguay) \\ ${ }^{2}$ Departamento de Física de la Tierra, Astronomía y Astrofísica I, Universidad Complutense de \\ Madrid, (España)
}

*Corresponding author: vero.martin.gomez@gmail.com

\begin{abstract}
ENSO exhibits different flavors with worldwide impacts. However, the associated teleconnections with subtropical South America (SSA) are still controversial and modelling studies are needed. Here, we analyze the Southern Hemisphere (SH) circulation anomalies and the impacts over SSA during the austral summer due to different El Niño patterns (Canonical and El Niño Modoki). The analysis is performed considering reanalysis data and two different Atmospheric General Circulation Models (SPEEDY and UCLA - AGCM).
\end{abstract}

Results from reanalysis show that positive precipitation anomalies develop over SSA during Canonical El Niño events. These anomalies are induced through an increase of upper level cyclonic vorticity advection and a stronger low-level southward moisture transport. However, in El Niño Modoki events, rainfall anomalies are observed over SSA only for the strongest events.

Both models are able to reproduce the precipitation signal over SSA in the Canonical El Niño case, although the underlying physical mechanism depends on the model. In SPEEDY, the increased rainfall is due to an increase of the moisture transport toward SSA, while in UCLA - AGCM it is related to both, an increase of the low-level moisture transport toward SSA and the increase of upper level cyclonic vorticity advection. The precipitation signal associated with El Niño Modoki is more controversial. While UCLA AGCM suggests a rainfall increase over SSA, SPEEDY, in agreement with observations, does not show any statistically significant signal. However, the upper level circulation anomalies reproduced by UCLA AGCM are more consistent with reanalysis than those from SPEEDY, which makes UCLA - AGCM to be more reliable. This result suggests increased rainfall over SSA during El Niño Modoki

\section{Introduction}

The El Niño - Southern Oscillation (ENSO) is the main mode of interannual climate variability and is a major driver of anomalies worldwide. Its positive (negative) phase, named El Niño (La

This article has been accepted for publication and undergone full peer review but has not been through the copyediting, typesetting, pagination and proofreading process which may lead to differences between this version and the Version of Record. Please cite this article as doi: $10.1002 /$ joc. 6577 
Niña), consists in an anomalous warming (cooling) over the equatorial Pacific and is known to have impacts on precipitation and temperature patterns in different regions (e.g., Cai and Cowan, 2009; Reason and Rouault, 2002; Tedeschi et al., 2013; Sulca et al., 2018; Barreiro, 2017; Ropelewski and Halpert, 1986; King et al., 2018; López - Parages et al., 2015; Villafuerte and Matsumoto, 2015; Zhang et al., 2016). The traditional El Niño events are commonly known as Canonical El Niño and are characterized by maximum tropical SST anomalies located in the eastern equatorial Pacific, a reason for also called it as Eastern Pacific El Niño or EP. However, at the beginning of the $21^{\text {st }}$ century, some studies showed that the region of maximum tropical SST variability shifted westward since the 1990s, taking place in the central Pacific rather than in the eastern Pacific (e.g., Xiang et al., 2013). This new type of El Niño event was firstly named "dateline El Niño" by Larkin and Harrison, (2005), and two years later "El Niño Modoki" by Ashok et al., (2007). Other names as Central El Niño (CP) or warm pool El Niño refer also to this type of ENSO.

Both types of ENSO events may change under global warming. In particular, a recent study has indicated that the frequency of "El Niño Modoki" will increase in the future, while the strong “Canonical El Niño" will become more frequent (Cai et al., 2018). Thus, the associated impacts of both events merit a deeper understanding and in this study we focus on the positive phase of these two ENSO types.

Focusing on the austral summer season (here defined as December - January - February) and on the Southern Hemisphere ( $\mathrm{SH})$, one of the most affected regions by this phenomenon is South America (SA; Tedeschi et al., 2013; Tedeschi et al., 2015; Grimm et al., 2000; Barreiro 2017). Observational and modeling studies have shown that the mechanism through which ENSO influences SA depends on the latitude: While in the tropics the influence takes place through changes in the Walker circulation and equatorial waves, at extra - tropical latitudes it is through the generation and propagation of Rossby wave trains (e.g., Tedeschi et at., 2013; Sun et al., 2013; Andreoli et al., 2017). Transition regions such as Subtropical South America (SSA, Figure 1) can be impacted by both. Additionally, the changes in the Walker circulation and extratropical Rossby wavetrains strongly depend on the location of maximum SST anomalies over the equatorial Pacific (Weng et al., 2009; Tedeschi et al., 2013; Sun et al., 2013; Tedeschi et al., 2015; Hill et al., 2009; Hill et al., 2011; Andreoli et al., 2017; Sulca et al., 2018; Barreiro 2017).

At tropical latitudes, the main difference between the two types of El Niño events seems to be located over the eastern Pacific, where there is an anomalous ascent during the Canonical El Niño 
but an anomalous descent during El Niño Modoki (Yuan and Yang., 2012; Sun et al., 2013; Tedeschi et al., 2013). In both El Niño cases, anomalous subsidence takes place over tropical SA, being stronger for the Canonical El Niño case, thus favoring the development of large negative precipitation anomalies (see Tedeschi et al., 2013; Andreoli et al., 2017). This result, found in reanalysis, also agrees with those obtained by Hill et al., (2009) using an atmospheric general circulation model (AGCM).

At extratropical latitudes, SSA is the main region influenced by El Niño. Observational studies (Tedeschi et al., 2015; Tedeschi et al., 2013; Barreiro 2017; Sun et al., 2013; Weng et al., 2009) and modeling (Hill et al., 2011) have shown that the anomalous geopotential height pattern at $200 \mathrm{hPa}$ excited by ENSO varies depending on El Niño event type. Studies suggest that the Canonical El Niño events induce positive precipitation anomalies over SSA through (1) an increase of the cyclonic vorticity advection aloft which increases baroclinicity over SSA and/or (2) an increase of the moisture transport toward SSA from the Amazon basin at low-levels (e.g., Silva and Ambrizzi, 2006; Hill et al., 2009; Tedeschi et al., 2013).

The impact of El Niño Modoki on SSA rainfall is more controversial. Based on partial regression between precipitation and El Niño Modoki index, Weng et al., (2009) showed a negative and statistically significant signal over SSA (see their Fig 4). Results from Tedeschi et al., (2013) and Brito (2011), based on composite precipitation maps, also point out on this direction although the negative precipitation signal over SSA is not statistically significant. On the other hand, there are also studies in the literature suggesting a statistically significant increase of SSA precipitation during El Niño Modoki (Sulca et al., 2018). In Andreoli et al., (2017) the signal over SSA is also positive but statistically significant only over some portions of SSA. Differences in these studies can arise from the period considered, the dataset employed and the methodology used to define $\mathrm{El}$ Niño Modoki. Therefore, it is not clear in the literature whether the impact of El Niño Modoki on SSA precipitation anomalies is positive or negative during summertime.

Although there exist some modeling studies analyzing the influence of El Niño Modoki on SA, most studies analyze reanalysis data. In the $\mathrm{SH}$, the quality of reanalysis improved substantially after 1979 with the coverage of satellites, and thus it is reasonable to consider only the last four decades. As consequence, we have very few cases of Canonical and Modoki El Niño events, which weakens any inference obtained using only reanalysis. Therefore, to study the influence of these two different El Niño types on SSA with more robustness we need to turn to experiments with AGCMs, and that's the approach we follow here. 
The paper is structured as follows: on section 2 we explain the data and methodology considered. On section 3, we review the impacts of the two El Niño flavors considering reanalysis data and, on section 4 we show and discuss the simulated results from two different AGCMs. Finally, on section 5 we present a summary and the main conclusions of the present work.

\section{Data and Methodology}

\subsection{Data}

This study is performed using an atmospheric reanalysis dataset as well as the output from two different AGCMs: the ICTP-AGCM from The Abdus Salam International Center for Theoretical Physics (hereafter called SPEEDY; Molteni, 2003; Kucharski et al., 2006), and the UCLA AGCM from the University of California (hereafter called UCLA - AGCM; Reichter et al., 2008). The comparison between two models is useful because it increases the robustness of the results. The UCLA - AGCM used here is the version 7.1, coupled to the Simplified Simple Biosphere Model (SSiB; Xue et al. 1991), with a resolution of $2.5^{\circ}$ longitude by $2^{\circ}$ latitude and 29 vertical layers (14 in the stratosphere), as described in Ma et al. (2013). The parameterization of cumulus convection (Pan and Randall, 1998) is based on the prognostic version of Arakawa and Schubert (1974). Radiative processes follow Harshvardhan et al. (1987, 1989), and the PBL parameterization is based on the mixed-layer approach of Suarez et al. (1983), revised by Li et al. (2002). Surface heat fluxes calculations use the bulk formula from Deardorff (1972), modified by Suarez et al. (1983). For more details of the model see Arakawa (2000) and Mechoso et al. (2000). This model has been widely used for climate variability studies, including the impact of SST modes on tropical climate, like ENSO (Mohino et al., 2011) or the Atlantic Niño (Losada et al., 2010) and the simulation of the South American climate (Ma et al., 2011).

Regarding SPEEDY, the version used here is the 4.1 with a resolution of about $3.75^{\circ}$ in the horizontal and 8 vertical layers ( 2 in the stratosphere). The parametrization of convection follows a simplified version of the mass - flux scheme developed by Tiedke (1993), which is activated where conditional instability is present and where humidity in the planetary boundary layer (PBL) exceeds a prescribed threshold (more details in Molteni., 2003). Radiative processes and clouds properties are also parametrized following Corbertta (1999). Surface momentum and energy fluxes are defined by bulk aerodynamic formulas with different exchange coefficients between land and sea (chapter 4, Hartmann 1994). A more detail description of all these parametrization schemes can be found on https://www.ictp.it/research/esp/models/speedy.aspx. Finally, this model 
has been previously used to investigate impacts of ENSO on South America (e.g., Martín Gómez and Barreiro, 2016; Barreiro and Diaz, 2010).

The reanalysis data considered in this study are the monthly mean values of horizontal winds at $850 \mathrm{hPa}$ (V850) and geopotential height at 200hPa (Z200) from NCEP/DOE Reanalysis 2 (Kanamitsu et al., 2002). Monthly mean Sea Surface Temperature (SST) from ERSSTv4 (Huang et al., 2014) and the NOAA interpolated Ongoing Longwave Radiation (OLR, Liebmann and Smith, 1996) are also used. Finally, we also considered precipitation (PCP) data from CMAP (Xie and Arkin, 1997). While SST presents a resolution of $2^{\circ} \times 2^{\circ}$, V850, Z200, PCP and OLR have a resolution of $2.5^{\circ} \times 2.5^{\circ}$. All of them are provided by NOAA/OAR/ESRL PSD, Boulder, Colorado and can be found on https://www.esrl.noaa.gov/psd/. We also considered the monthly mean values of the velocity potential $(\chi)$ and associated divergent winds $\left(\mathrm{V}_{\chi}\right)$ at $200 \mathrm{hPa}$. To obtain these fields, we first calculated $\chi$ solving the Poisson's equation: $\underline{\nabla} \cdot V=\underline{\nabla}^{2} \chi$, and afterwards we computed $\mathrm{V}_{\chi}$ as the gradient of $\chi\left(\mathrm{V}_{\chi}=\underline{\nabla} \chi\right)$. We focus on the austral summer season defined from December to February (DJF) during the period 1979 - 2016, resulting in 36 seasons. For the case of the models, we consider the same variables except for PCP, which it is replaced by the OLR given the known systematic errors that models present on PCP field (see Barreiro and Diaz, 2010 for the SPEEDY case and Ma et al., 2013 for UCLA - AGCM).

\subsection{Methodology}

The study is carried out in two parts. In the first one we study the $\mathrm{SH}$ atmospheric response to different El Niño flavors using regression analysis with the observational and reanalysis data aforementioned. In the second part, we performed sensitivity experiments using the two models.

To address the first part, we calculated the two different ENSO indices. The Niño3 index was computed as the DJF SST anomaly averaged over the region $\left(220^{\circ} \mathrm{E}-270^{\circ} \mathrm{E} ; 5^{\circ} \mathrm{N}-5^{\circ} \mathrm{S}\right)$, while $\mathrm{El}$ Niño - Modoki index (MI) was calculated according to the improved definition given by Li et al., (2010): $\mathrm{MI}=3 \cdot[\mathrm{SSTa}]_{\mathrm{A}}-2 \cdot[\mathrm{SSTa}]_{\mathrm{B}}-[\mathrm{SSTa}]_{\mathrm{C}}$, where $[\mathrm{SSTa}]_{\mathrm{A}}$ refers to the average of the DJF SST anomalies over the box $A=\left[165^{\circ} \mathrm{E}-220^{\circ} \mathrm{E}, 10^{\circ} \mathrm{S}-10^{\circ} \mathrm{N}\right],[\mathrm{SSTa}]_{\mathrm{B}}$ over the region $\mathrm{B}=\left[250^{\circ} \mathrm{E}\right.$ $\left.-290^{\circ} \mathrm{E}, 15 \mathrm{~S}-5 \mathrm{~N}\right]$ and $[\mathrm{SSTa}]_{\mathrm{C}}$ over the domain $\mathrm{C}=\left[125^{\circ} \mathrm{E}-145^{\circ} \mathrm{E}, 10^{\circ} \mathrm{S}-20^{\circ} \mathrm{N}\right]$. After that, we computed the monthly anomalies of PCP, OLR, Z200, V850hPa, $\chi$ and $\mathrm{V}_{\chi}$ fields by removing the seasonal cycle, averaged over DJF season, and calculated the regression of each field onto El Niño indices over the period (1979 - 2016). Results are shown in Figures 3, 4 and 5, and will be analyzed in section 3 . 
In the second part we performed three types of sensitivity experiments with each model. Each one consists in an ensemble of 11 simulations, all of them initialized with different atmospheric initial conditions but all having the same SST as boundary conditions. Each simulation started on October $1^{\text {st }}$ and runs until March $31^{\text {st }}$. The three experiments are: (1) CONTROL : 11 simulations obtained considering as boundary condition the climatological SST averaged over the period (1979 - 2016), (2) Canonical: 11 simulations performed considering as boundary condition the SST pattern associated to Niño3 index superimposed to the SST climatology over the period (1979 - 2016), and (3) Modoki: 11 simulations carried out considering as boundary conditions the SST pattern associated to El Niño - Modoki index superimposed to the SST climatology over the period (1979 - 2016). In the case of UCLA - AGCM, the change in the initial conditions was made by adding randomly perturbations in temperature, humidity and velocity fields. In the case of SPEEDY, the different initializations were performed by randomly releasing a diabatic forcing during the first days of the simulation.

The SST anomaly patterns superimposed to the climatology were computed as the regression maps of monthly SST anomalies onto the Niño3 and El Niño Modoki indices over the period 1979 - 2016. This results in 6 maps, one per month from October to March. They were multiplied by 1.5 in order to make these typical El Niño patterns more intense. Therefore, we obtained maximum SST anomaly values in our boundary conditions of $2^{\circ} \mathrm{C}$ for Canonical El Niño and $1.0^{\circ} \mathrm{C}$ for El Niño Modoki events. Figure 2 shows as an example of the monthly SST anomaly patterns for December, January and February. Given that the study is focused on analyzing the atmosphere response to only El Niño signal, the SST anomalies outside of the tropical Pacific were adjusted to zero.

The construction on an ensemble allows filtering out most of the internal atmospheric variability and focusing on the SST forced response by taking the ensemble mean (Saravanan and Chang, 2000; Barreiro and Tippmann, 2008; Barreiro, 2010). Here, to isolate the atmospheric response to different Niño events, we consider the ensemble mean of each experiment and subtract the CONTROL case from the Canonical and Modoki experiments. We also consider individual ensemble members to study the intra-ensemble dispersion, providing a measure of predictability in a perfect - model - approach.

Additionally, given that results from regression analysis are not directly comparable with model outputs because they include all the years, we also computed the PCP and Z200 composite maps of the stronger Canonical and El Niño Modoki years. Strong Canonical (El Niño Modoki) were 
defined as those when the Nino3 index (El Niño Modoki index) is larger than $0.7 \sigma_{\mathrm{N}}\left(0.7 \sigma_{\mathrm{M}}\right)$, where $\sigma_{N}\left(\sigma_{M}\right)$ is the standard deviation of Niño3 (El Niño Modoki) index (Tedeschi et al., 2013). For the case of El Niño Modoki, an additional constrain was considered, requiring the average of the SST anomalies over box A to be larger than $0.7 \sigma_{\mathrm{SSTa}}$, where $\sigma_{\mathrm{SSTa}}$ is the standard deviation of the SST anomalies in the region A (like in Tedeschi et al., 2013). Finally, we considered as neutral years those ones when the absolute value of the Nino3 index and El Niño Modoki index is lower than $0.7 \sigma_{i}$, being $\mathrm{i}=\mathrm{N}$ or $\mathrm{M}$ depending on the type of El Niño. Table 1 summarized the year's classification attending to this criterion.

Finally, the horizontal quasi - stationary wave activity (Fs) was also computed in order to analyze the Rossby wave propagation. We considered the definition given by Plumb (1985)

$$
\vec{F}_{S}=\left(\begin{array}{l}
F_{x} \\
F_{y}
\end{array}\right)=\frac{P o}{P r e f} \cos (\phi)\left(\begin{array}{l}
v^{\prime 2}-\frac{1}{2 R} \Omega \sin (2 \phi) \cdot \frac{\partial v^{\prime} z^{\prime}}{\partial \lambda} \\
-u^{\prime} v^{\prime}+\frac{1}{2 R \Omega \sin (2 \phi)} \cdot \frac{\partial u^{\prime} z^{\prime}}{\partial \lambda}
\end{array}\right)
$$

where Po is the pressure at the level where $\vec{F}_{s}$ is computed, in our case $200 \mathrm{hPa}$, Pref is the pressure at a reference level of $1000 \mathrm{hPa}, \phi$ is the latitude, $R$ is the Earth's radius, $\Omega$ is the angular rotation rate of the Earth, $u^{\prime}$ and $v^{\prime}$ are the eddy horizontal geostrophic wind components at $200 \mathrm{hPa}$ averaged over DJF, and $z^{\prime}$ is the eddy geopotential height at $200 \mathrm{hPa}$ averaged over DJF.

\section{Observed changes in the SH circulation and precipitation over SSA during different El Niño patterns.}

\subsection{Canonical El Niño}

Figure 3 shows the regression maps for the Canonical El Niño. Rainfall anomalies are characterized by strong positive (negative) values over SSA (northern Amazon) region (Figure 3(a)). Focusing on Figure 3(b), it is possible to see that the upper level circulation over the SH is characterized by a short Rossby wave that is apparently excited in the central - tropical Pacific characterized by an anomalous cyclonic circulation around $\left(38^{\circ} \mathrm{S}, 265^{\circ} \mathrm{E}\right)$ and an anomalous anticyclonic circulation over the northeast of SSA (centered around $\left(28^{\circ} \mathrm{S}, 315^{\circ} \mathrm{E}\right)$ ). These two circulation anomalies induce a strong geopotential height gradient over SSA that favors advection of cyclonic vorticity over there, consistent with previous studies (e.g., Grimm et al., 2000). 
Another Rossby wave train seems to emanate from the central - west subtropical Pacific (around $45^{\circ} \mathrm{S}, 200^{\circ} \mathrm{E}$ ) propagating southeastward (Figure 3(b)).

The low level wind anomalies over the extra-tropics are consistent with the geopotential heigh anomalies in upper levels (compare Figure 3(b) and (c)), suggesting a barotropic behavior of the atmosphere. Over SA, anomalous northerly low-level flow develops increasing the transport of humid and warm air toward SSA (see Figure 3(c)). The combination of more transport of moisture toward SSA at lower levels and the increase of the cyclonic vorticity advection in upper levels induces an anomalous increase of the precipitation over SSA (see Figure 3(a)) as noted in the introduction.

In the tropics upper level divergent wind anomalies spread from the central to the eastern equatorial Pacific, in agreement with Sun et al. (2013) and Weng et al., (2009), although the maximum is located over the central west equatorial Pacific, around $200^{\circ} \mathrm{E}$ (see Figure 3(d)). This anomalous upper level divergence of the $\mathrm{V}_{\chi}$ represents the ascent branch of the anomalous Walker circulation, while the descending branch is located mainly over the northern Brazil, where an anomalous convergence of the $\mathrm{V}_{\chi}$ can be found (see Figure 3(d)). This is consistent with the negative precipitation anomalies over northern SA (see Figure 3(a)), and agrees with Weng et al., (2009) and Tedeschi et al., (2013). Additionally, related to this upper level $\mathrm{V}_{\chi}$ convergence, anomalous wind divergence develops at lower levels over northern Brazil, which in turn favors an increase in the moisture transport toward the subtropics, representing a weakening of the regional Hadley cell. Therefore, in this case the low-level flow anomaly in subtropical SA is a combination of the changes of the upper - level barotropic flow and the local Hadley circulation anomaly.

\subsection{El Niño Modoki}

Figure 4 shows the regression maps for El Niño Modoki. Comparing Figures 3(a) and 4(a), it is possible to see that precipitation anomalies over SA present the same sign over the northern SA, but cover a smaller area. However, unlike Canonical El Niño case, the PCP signal over SSA is weak and not significant. This result is consistent with the controversy existent in the literature, where it is possible to find studies suggesting a rainfall increase during El Niño Modoki (e.g. Andreoli et al., (2017) and Sulca et al., (2018)), others showing a reduction in precipitation (e.g., Weng et al., 2009), and others in which there is no statistically significant precipitation signal over SSA (Tedeschi et al., 2013 and Brito, 2011). 
Focusing on the upper level response, there is an anomalous anticyclonic circulation over SSA, around $\left(30^{\circ} \mathrm{S}, 305^{\circ} \mathrm{E}\right)$ and an anomalous cyclonic circulation that extends over the southeast Pacific and southern Chile. The conjunction of these two anomalous circulations favors the upper level advection of cyclonic vorticity over southeastern SSA, and is consistent with the existence of a positive PCP anomaly band from La Plata River to the Southern Atlantic Ocean (see Figure 4(a)). In comparison with the Canonical case, the position and structure of the anomalous circulations in the cyclonic - anticyclonic system around SA is not the same, and has weaker amplitude thus inducing smaller rainfall anomalies and in a different area.

Overall, the Z200 anomalies in El Niño Modoki have a different shape from the Canonical El Niño and are weaker, which could be related to two factors: (1) the change in the position of the positive SST anomalies over the equatorial Pacific (compare first and second columns on Figure 2), and (2) the weaker intensity that characterizes the SST anomalies associated to the El Niño Modoki events (e.g., see Figure 2 from Tedeschi et al., 2013). Related to the latter, it has been shown that larger SST anomalies over the tropical Pacific induce a stronger response in the circulation anomalies at both, upper and lower levels (Barreiro and Tippman, 2008). On the other hand, and considering that the standard deviation of the Canonical El Niño and El Niño Modoki indices is 0.99 and 1.63, respectively, the smaller regression coefficients observed for the case of El Niño Modoki would suggest that the atmosphere is more sensitive to changes in the eastern equatorial Pacific than in the central Pacific.

As in the Canonical El Niño case, circulation anomalies in the extratropics show a barotropic behavior. However, unlike in the Canonical El Niño case, no increase of moisture transport from the tropics towards SSA is observed. During El Niño Modoki events, the increase of the northerlies takes place southward of $25^{\circ} \mathrm{S}$, suggesting a weaker southerly moisture flow toward SSA. This is consistent with a weaker extratropical teleconnection toward SSA as shown in Figure 3(b).

$\mathrm{V}_{\chi}$ presents an anomalous upper level divergence maximum confined to the western equatorial Pacific, around $180^{\circ} \mathrm{E}$, consistent with anomalous low-level wind convergence (Figure 4(c); in agreement with Sun et al., 2013 and Weng et al., 2009). The westward shift of the anomalous upper level divergence of $\mathrm{V}_{\chi}$ with respect to Canonical El Niño (compare Figure 3(d) and 4(d)) is consistent with the westward shift of the SST anomalies associated to El Niño Modoki (compare first with second columns in Figure 2) and with the literature, (e.g., Weng et al., 2009; Brito, 2011; Sun et al., 2013). 
The descending branch of the anomalous Walker circulation develops over the eastern equatorial Pacific and also over northeastern Brazil, where anomalous $\mathrm{V}_{\chi}$ convergence can be observed in Figure 4(d) (in agreement with Tedeschi et al., 2013; Sun et al., 2013; Weng et al., 2009). Comparing with the case of the Canonical El Niño, the westward position and weaker intensity of the anomalous upper level wind convergence in northeast Brazil during El Niño Modoki probably does not significantly weaken the regional Hadley cell over South America (compare Figures 3(d) and 4(d)). Thus, this component of the circulation does not produce strong low-level circulation anomalies and, together with the weaker Z200 gradient over SSA, they do not favor an increase in the northerlies and in the moisture flow toward SSA.

\subsection{Observational relationship between PCP and OLR}

Figure 5 (a) and (b) show the regression map of OLR anomalies onto the Canonical El Niño and El Niño Modoki indices, respectively. Comparing Figure 5(a) with 3(a), it is possible to see that the spatial distribution of the PCP and OLR anomalies is almost the same, but with an opposite sign. In particular, while positive (negative) PCP (OLR) anomalies develop over SSA during the Canonical El Niño event, negative (positive) PCP (OLR) anomalies can be detected over northern South America. A similar behavior can be observed for the case of El Niño Modoki when comparing Figure 5(b) and 4(a), although in this case there are no significant PCP and OLR anomalies over SSA. Therefore, the observational results suggest that OLR anomalies can be used as an indication of precipitation anomalies over SSA. Given that models present important systematic errors in PCP, this observational relationship allows us to use simulated OLR as representative of precipitation anomalies in the models.

\subsection{Strong El Niño events}

As explained in section 2.2 in order to better compare with model simulations we also computed the composite maps of PCP and Z200 for the strongest Canonical and El Niño Modoki events (Figure 6). For the Canonical El Niño case composite and regression analyses provide similar results suggesting a linear behavior of the atmosphere in response to this El Niño type (compare Figure 6(a) with 3(a), and 6(b) with 3(b)). Additionally, the quasi - stationary wave activity, Fs, suggests the presence of a long Rossby wave propagating from the western subtropical South Pacific toward southeast until $\left(55^{\circ} \mathrm{S}, 250^{\circ} \mathrm{E}\right)$, where it is deflected northeastward (Figure 6(b)). Additionally, there is indication of a short-wave train characterized by the subtropical eastern 
South Pacific cyclone in $\left(28^{\circ} \mathrm{S}, 315^{\circ} \mathrm{E}\right)$ and the northeastern SSA anticyclone located around $\left.\left(28^{\circ} \mathrm{S}, 315^{\circ} \mathrm{E}\right)\right)$.

For the El Niño Modoki case, the pattern of Z200 anomalies from composite and regression analyses present a similar distribution (compare Figure 6(d) with Figure 4(b)). However, unlike the regression analysis, the composite map of PCP shows a statistically significant signal over SSA (compare Figure 6(c) with Figure 4(a)), suggesting that the strongest El Niño Modoki events induce positive rainfall anomalies over SSA. On the other hand, Fs shows a wave propagation from the anomalous cyclonic circulation located over the southwestern SA toward the anomalous anticyclone over the southeastern Brazil (Figure 6(d)).

Given the large similarity between regression and composite maps the simulated Z200 composite can be compared with any of them.

\section{Simulated response to different EI Niño patterns}

\subsection{Results from SPEEDY model}

Figure 7 shows the composite maps of Canonical El Niño impacts obtained from SPEEDY. As in observations, the model captures a decrease (increase) of OLR anomalies over SSA (northern SA). In upper levels, there is a wave excited in the subtropical western Pacific but it is shifted westward with respect to the one observed in the reanalysis (compare Figure 7(b) and 6(b) or 3(b)). Also, there is no sign of the short wave that is excited toward SA in Figure 6(b) and that induces a trough over SSA.

In the extratropics the SH circulation presents a barotropic behavior (compare Figures 7(b) and (c)). Additionally, in agreement with the lower level circulation anomalies seen in the reanalysis, over SA there is an increase of the northerly winds that transport moisture toward SSA (compare Figure 3(c) and 7(c)).

Figure 7(d) shows that the maximum upper level divergence is located over the central equatorial Pacific, around the $220^{\circ} \mathrm{E}$, where anomalous low-level wind convergence takes place (compare Figures 7(c) and 7(d)). The anomalous upper level divergence is about $20^{\circ}$ shifted eastward compared with the reanalysis (Figures 3(d) and 7(d)). The model correctly reproduces the positive eastward $\chi$ gradient and the anomalous upper level $\mathrm{V}_{\chi}$ divergence from the central to the eastern equatorial Pacific, suggesting that the ascent associated with the anomalous Walker 
circulation in Canonical El Niño spreads from the central Pacific to the eastern Pacific. The descending anomalous Walker circulation branch would be mainly located between the southern Colombia, Venezuela and French Guiana, and northern Brazil, where an anomalous and statistically significant $V_{x}$ convergence can be found (see Figure 7(d)), together with positive OLR anomalies (Figure 7(a)). The weakening of the regional Hadley cell is therefore the reason of the increased northerlies toward SSA.

Figure 8 shows the composite maps for the case of El Niño Modoki. The OLR anomalies show no statistically significant signal over SSA, as in observations (compare Figure 8(a) and 5(b)). Upper - level Z200 anomalies show a wave train excited eastward New Zealand which does not reach South America/South Atlantic (Figure 8(b)).

Regarding the divergent component of the circulation, Figure 8(d) shows that the anomalous upper level $\mathrm{V}_{\chi}$ divergence is mainly confined over the western equatorial Pacific, between $170^{\circ} \mathrm{E}$ and $210^{\circ} \mathrm{E}$. This westward shift of the maximum anomalous $\mathrm{V}_{\chi}$ divergence with respect to Canonical El Niño is consistent with the results obtained from reanalysis data. An anomalous convergence of $\mathrm{V}_{\chi}$ is found over northeast Brazil (see Figure 8(d)). However, this convergence does not seem to be strong enough to weaken the regional Hadley cell and induce an increase of the low-level northerly wind in South America (see Figure 8(c)).

\subsection{Results from UCLA - AGCM.}

Figure 9(a) shows the OLR composite map of Canonical El Niño obtained from UCLA - AGCM experiments. A statistically significant reduction (increase) of the OLR anomalies over SSA (northern SA), similar to observations (compare Figure 9(a) and 5(b)) is shown, suggesting anomalous increase (reduction) of rainfall over SSA (northern SA). The upper level circulation shows a Rossby wave train that emanates eastward of New Zealand and propagates to the southeast as seen in the reanalysis (compare Figures 9(b) and 6(b)). There is also evidence of a shorter wave train with centers in the eastern Pacific and the south Atlantic that induce a trough over SSA, but weaker and displaced southward compared to reanalysis. Nonetheless, these anomalies increase advection of cyclonic vorticity over SSA favoring the increase of baroclinicity and the development of ascent motions.

At lower levels, there is a statistically significant increase of the northerlies that transport moisture toward subtropical latitudes (see Figure 9(c)). The combination of upper and low level anomalies favors the increase of precipitation anomalies seen in SSA (see Figure 9(a)). 
Anomalous upper level $\mathrm{V}_{\chi}$ divergence is located over the western equatorial Pacific, around $180^{\circ} \mathrm{E}$, shifted about $20^{\circ}$ to the west compared to the reanalysis (compare Figures 3(d) and 9(d)). In this case, the ascent motions associated to the anomalous Walker circulation would be mainly confined over the central - west equatorial Pacific, different from reanalysis where anomalous ascent motions develop from the central to the eastern equatorial Pacific. There is upper level convergence of $\mathrm{V}_{\chi}$ over northern SA which also appears in the reanalysis (see Figures 9(d) and 3(d)). Even though the regional Hadley circulation weakens, changes are very small and probably do not contribute much to changes in surface anomalies.

Figure 10(a) shows the OLR anomaly composite map for El Niño Modoki obtained from UCLA AGCM. There is a positive and statistically significant signal over northwest SA and the continental part of the South Atlantic Convergence Zone (SACZ), and a negative statistically significant signal over northwest SSA. These results suggest than El Niño Modoki induces a reduction (increase) of precipitation over the SACZ and northern SA (SSA), which does not coincide with results from regression analysis (compare Figures 4(a) and 10(a)). Additionally, the position of the OLR anomalies over SSA change with respect to the case of Canonical El Niño, being located more northwestward during El Niño Modoki (compare Figures 9(a) and 10(a)).

The simulation shows in upper levels a Rossby wave train that emanates from the subtropical central Pacific, eastern of New Zealand, and propagates towards the southeast (see Figure 10(b)). Comparing with reanalysis (Figure 6(d)), it is possible to see a second short wave emanating from the eastern Pacific that generates an anticyclonic anomaly off Uruguay and favors dynamic lift over SSA. In the reanalysis (Figure 6(d)), the cyclonic anomalies associated with this short wave and with the one emanating from the central Pacific are joined over southern Chile. Here, the use of the model allows to distinguish between the two and increase their statistical significance.

Note that in low-levels northerly wind from northern SA at $20^{\circ} \mathrm{S}$ are weakened, and thus do not contribute to increase rainfall over SSA (see Figure 10(c)). Also, trades are weakened in the Amazon region, contrary to observations (see Figure 10(c) and compare with 4(c)).

4.3 Discussion of models' results.

4.3.1 Canonical El Niño

This article is protected by copyright. All rights reserved. 
Both models are able to reproduce the main features of the OLR anomaly pattern over SA associated to the Canonical El Niño, although with small changes in the location of the maximum anomalies. However, the underlying physical mechanisms through which the influence takes place change depends on the model.

Focusing on SSA, results from reanalysis showed that the increased rainfall is due to both, an increase of the upper level advection of cyclonic vorticity and the intensification of the lower levels moisture transport toward SSA. The increased northerly winds are in turn consequence of the changes in rotational and divergent parts of the wind field. Regarding model simulations, in UCLA - AGCM the increased rainfall is related to the increased upper level advection of cyclonic vorticity and the increase of the lower level moisture transport toward SSA, the latter being mainly associated with anomalies of the rotational wind component since the gradient of the velocity potential anomalies is small. The more realistic Z200 response is given by UCLA AGCM. As in reanalysis, this model presents evidence of two Rossby waves, one that emanates from eastward New Zealand and propagates southeastward, and another shorter one with centers in the eastern Pacific and the south Atlantic (compare Figure 10(b) and 6(b)). On the other hand, in SPEEDY the Z200 response only presents a large Rossby wave train emanating from northeast New Zealand that propagates to the south (Figure 7(b)), and positive rainfall anomalies over SSA are due to increased northerlies at low-levels that arise from anomalies in the divergent component of the wind.

Differences in the models' response to Canonical El Niño events could be associated with different configurations of the upper level mean flow, because the trajectory of quasi-stationary Rossby waves depends on the position of the jet stream. Comparing the climatological upper level mean flow in reanalysis, SPEEDY and UCLA - AGCM CONTROL runs (Figures 11(a), (c) and (e), respectively) it is possible to see that the zonal mean flow in UCLA - AGCM presents a more realistic representation than in SPEEDY, where the jet stream is located northward, and is more intense and zonally symmetric than in reanalysis. This is consistent with the fact that teleconnections at $200 \mathrm{hPa}$ are more realistic in UCLA-AGCM.

Focusing on the upper level response to the Canonical El Niño in SPEEDY, the anomalous cyclonic circulation over northeastern New Zealand associated to the long Rossby wave train on Figure 7(b) grows up between the positive and negative u200 anomalies located to the east/northeast of New Zealand on Figure 11(c), and it mainly presents a meridional propagation towards the south. Thus, the SPEEDY limitation to reproduce the eastward component of the 
wave propagation is related to the absence of westerly winds to the south of $55 \mathrm{~S}$ in this model (see Figure 11(c)). In the case of UCLA - AGCM, the eastward component of the Rossby wave propagation is allowed because the upper level jet maximum is located to the south of the anomalous cyclonic circulation associated to the wave train and the basic state presents westerlies until $70^{\circ} \mathrm{S}$ (Figure 10(d)).

Despite the fact that SPEEDY does not reproduce any short Rossby wave emanating from the eastern subtropical Pacific, Z200 presents a trough over SSA during El Niño Canonical (Figure 7(b)). Its origin can be understood through the u200 anomalous response. Focusing on Figure 11(c) it is possible to see that the SPEEDY response to Canonical El Niño tends to move the upper level jet stream northward over the South Pacific. Taking a fixed latitude in the subtropics, the $\mathrm{u} 200$ anomalies are stronger in the South Pacific sector than in the Atlantic, and therefore the isotachs adopt a curvature of a trough when crossing SSA (see Figure 11(c)). Something similar happens in the UCLA - AGCM response to Canonical El Niño (Figure 11(e)). Therefore, while the trough over SSA in SPEEDY is due to the u200 anomaly in response to Canonical El Niño, in UCLA - AGCM the trough over SSA presents two contributions: the u200 anomaly in response to El Niño, and the influence of the shorter Rossby wave.

\subsubsection{Models' comparison for the El Niño Modoki case.}

For the case of El Niño Modoki, results from observations suggest a statistically significant increase of PCP over the northwestern SSA only during strong El Niño Modoki events (compare Figure 4(a) with 6(c)).

Focusing on the models, SPEEDY does not present a precipitation signal over SSA, while results from UCLA - AGCM suggest a rainfall increase over northwestern SSA through an anomalous intensification of the upper level advection of cyclonic vorticity. Despite the agreement between SPEEDY and the observations, UCLA - AGCM seems to better reproduce the circulation changes associated to El Niño Modoki. The limitations of SPEEDY, as mentioned before, are mainly related to the mean upper level zonal winds. Comparing Z200 in reanalysis and UCLA AGCM (Figures 4(b) and 10(b)), it is possible to see a long Rossby wave train that emanates from the subtropical central Pacific and propagates towards the east. Additionally, there is also a short wave emanating from the eastern Pacific that generates an anticyclonic anomaly off Uruguay and favors dynamic lift (Figure 10(b)). In the reanalysis, the cyclonic anomalies associated with this 
short wave and with the one emanating from the central Pacific are joined over southern Chile (see Figure 4(b) or 6(d)). Here, the use of UCLA - AGCM allows to distinguish between the two and increase their statistical significance. Additionally, the statistically significant and negative OLR anomalies developed in SSA during El Niño Modoki does not have to be inconsistent with reanalysis results, where no precipitation signal was found. One reason for this could be the fact that the sensitivity experiments performed here for El Niño Modoki case present maximum SST anomalies of about $1^{\circ} \mathrm{C}$. Looking at the typical SST anomalies during El Niño Modoki events (see Figure 2 from Tedeschi et al., 2013, for example) this intensity would be rather related to the strongest El Niño Modoki events. However, in the regression analysis all the El Niño Modoki events are considered. Therefore, these results from UCLA - AGCM would suggest that only the strong El Niño Modoki events could produce positive rainfall anomalies over SSA.

Finally, in the case of SPEEDY, the Z200 anomaly pattern shows an upper level Rossby wave train that emanates to the east of New Zealand (Figure 8(b)), between the negative and positive u200 anomalies over the western subtropical South Pacific on Figure 11(d). Its propagation is mainly to the east and coincides with the position of the jet stream in the South Pacific (Figure 11(d)), suggesting that this Rossby wave could be trapped in the jet.

\subsubsection{Comparison Canonical versus Modoki.}

The SST anomalies associated to the strongest Canonical El Niño are twice as large as the ones of the strongest El Niño Modoki (compare first and second columns on Figure 2). In principle, one would expect the Z200a response to be stronger the larger the SST anomalies over the equatorial Pacific. This behavior is observed in SPEEDY (compare Figure 7(b) with 8(b)). However, results from UCLA - AGCM shows that the anomalous Z200 response to El Niño Modoki is much more intense than in the case of Canonical El Niño (compare Figures 9(b) and 10(b)). This unexpected result could be related to the signal - to - noise ratio in the experiments and the degree of intra ensemble variability in UCLA - AGCM simulations.

Figure 12 shows the spatial correlation coefficients of each Z200 - ensemble - member and the Z200 - ensemble - mean for SPEEDY and UCLA - AGCM. Correlations are computed considering the Pacific + Atlantic sector, here defined within the coordinates (150E-360E, 20S60S), and for the simulations of Canonical (solid line with circles) and Modoki El Niño (solid line with asterisks). The same results are found if correlations are computed considering only the 
Pacific sector. A large dispersion in the correlation coefficients within the ensemble members would suggest a large intra - ensemble variability and low signal-to-noise ratio, which results in a weak ensemble mean signal after the averaging procedure.

Focusing on Figure 12(b), it is possible to see that most of correlation coefficients in the case of El Niño Modoki in UCLA - AGCM are larger than 0.6, suggesting a large signal to noise ratio of El Niño Modoki in the atmospheric response in almost all the simulations. However, in the case of the Canonical El Niño, most of them are smaller than 0.6, which imply a weaker El Niño signal. Therefore, the atmospheric response to Canonical El Niño in UCLA - AGCM is weaker than that due to El Niño Modoki. These results suggest that UCLA - AGCM is more sensitive to the position of the SSTa than to the magnitude of the SSTa itself.

The atmospheric response to Canonical El Niño in SPEEDY is quite consistent among ensemble members as most correlation coefficients are around 0.4 (see line with asterisks on Figure 12(a)). However, the large dispersion of the correlation coefficients in the case of El Niño Modoki suggests a large intra - ensemble variability, which means that the atmospheric teleconnections observed for El Niño Modoki strongly depends on the ensemble member considered. This results in weak ensemble mean anomalies after the averaging procedure.

Finally, comparing results from both models with observations, it is possible to see that results from UCLA - AGCM are more realistic than the one obtained with SPEEDY. We hypothesize that this is related to the more realistic representation of the climatological upper level flow in UCLA - AGCM. These differences may be related to the models horizontal resolution, which is quite better in UCLA - AGCM than in SPEEDY. Additionally, while UCLA - AGCM presents 14 vertical levels representing the stratosphere, SPEEDY only has two. This poorer stratosphere resolution in SPEEDY may also contribute to the differences.

\section{Summary}

Considering two different models and data from reanalysis and observations, the present study analyses the reproducibility of the $\mathrm{SH}$ atmospheric response to two different flavors of the positive phase of ENSO focusing mainly on the impacts over SSA. These two flavors of ENSO, 
Canonical and Modoki, will likely change under global warming and thus a better knowledge of their impact is crucial.

Analysis of observations show that positive (negative) PCP (OLR) anomalies develop over SSA during Canonical El Niño events. The increased (decreased) rainfall (OLR) anomalies are due to the combination of two factors: (1) an increase of the cyclonic vorticity advection at $200 \mathrm{hPa}$ and (2) increased southward moisture transport toward SSA at $850 \mathrm{hPa}$ due to changes in both components of the circulation (rotational and divergent). For the El Niño Modoki case regression analysis does not show significant rainfall anomalies over SSA, but the composite analysis suggests that strong events can induce positive anomalies.

For Canonical El Niño events, both models reproduced negative PCP anomalies over northern Brazil and positive ones over SSA (see figures 7(a) and 9(a) and compare with 3(a)). However, the physical mechanism through which the positive PCP anomalies develop over SSA depends on the model. While in SPEEDY it is due to an increase in the northerlies that transport moisture from the Amazon Basin toward SSA, in UCLA - AGCM operate both, an increase of the cyclonic vorticity advection over SSA at $200 \mathrm{hPa}$ and the increase in the low-level northerlies (see Figures 7(b) and (c), and 9(b) and (c)), in agreement with observations (see Figures 3(b) and (c)). We hypothesize that differences arise due to the representation of the mean upper level flow, which is more realistic in the case of UCLA-AGCM (compare colored shaded Figures 11(a), (b) and (d)). Additionally, the increased moisture transport toward SSA in SPEEDY seems to be related with the divergent component of the wind field, while in UCLA - AGCM it would seem to be mainly related to anomalies in the rotational part of the flow.

In the case of El Niño Modoki, UCLA - AGCM shows positive rainfall anomalies over the northwestern SSA, which were induced by an increase of the cyclonic vorticity advection at $200 \mathrm{mb}$. The absence of an anomalous increase of the northerlies toward SSA in El Niño Modoki case may be related to the divergent part of the wind flow. Despite the fact that there is a statistically significant $\mathrm{V}_{\chi}$ convergence at $200 \mathrm{mb}$ over the northern SA, the signal is weak and it may not be strong enough to significantly induce an increase of the northerlies at surface. This is consistent with results from observations. On the contrary, SPEEDY does not show any statistically significant signal over there (see Figures 8(a) and 10(a)). Although there is an agreement between the PCP signal in SPEEDY and reanalysis over SSA, the model which better represent the observed Z200 anomaly pattern is UCLA - AGCM, and its results would suggest 
that precipitation anomalies could increase associated to the strongest El Niño Modoki events. Note that the models were forced with a pattern of El Niño Modoki with SST anomalies of about $1^{\circ} \mathrm{C}$, which corresponds with the strongest observed El Niño Modoki events.

Given that the SSTa are about $2^{\circ} \mathrm{C}$ in the Canonical El Niño case and about $1^{\circ} \mathrm{C}$ for El Niño Modoki, we expected the Z200 atmospheric response to be stronger in the Canonical El Niño case. This behavior is found in SPEEDY but not in UCLA - AGCM. A spatial correlation analysis of the Z200 atmospheric response in the Pacific + Atlantic sector revealed that the signal - to - noise ratio in the case of El Niño Modoki is stronger than in the case of the Canonical El Niño in UCLA - AGCM, suggesting that the signal of the latter is weaker due to large internal atmospheric variability. This suggests that UCLA - AGCM model is more sensitive to the location of the SSTa than the intensity of the SSTa.

To finish, the SPEEDY limitations to reproduce the Z200 anomaly pattern as response to Canonical El Niño and Modoki could be also related to the sensitivity of this model to the SSTa intensity over the equatorial Pacific. It is probable that increasing the intensity of the SST anomalies, the SPEEDY response improves. Therefore, a further study is needed in order to investigate the sensitivity of the SPEEDY response to the intensity of the SST anomalies over the equatorial Pacific. This will be addressed in a future work.

\section{References}

Andreoli RV, Oliveira SS, Kayano MT, Viegas J, Souza RAF and Candido LA. 2017. The influence of different El Niño types on the South American rainfall. International Journal of Climatology, 37(3), 1374-1390.

Arakawa A, Schubert WH. 1974. Interaction of a cumulus cloud ensemble with the large-scale environment, Part I. Journal of the Atmospheric Sciences, 31(3), 674-701.

Arakawa A. 2000: A personal perspective of the early years of general circulation modeling at UCLA. General Circulation Model Development: Past, Present, and Future: Proceedings of a Symposium in Honor of Professor Akio Arakawa, D. A. Randall, Ed., Academic Press, 1-65.

Ashok K, Behera SK, Rao SA, Weng H, and Yamagata T. 2007. El Niño Modoki and its possible teleconnection. Journal of Geophysical Research: Oceans, 112(C11). 
Barreiro M. 2010. Influence of ENSO and South Atlantic Ocean on climate predictability over southeastern South America. Clim. Dyn. 35: 1493-1508, doi: 10.1007/s00382-0666-9.

Barreiro M, Tippmann A. 2008. Atlantic modulation of El Nino influence on summertime rainfall over Southeastern South America. Geophys. Res. Lett. 3: L16704, doi: 10.1029/2008GL035019.

Barreiro M. 2017. Interannual variability of extratropical transient wave activity and its influence on rainfall over Uruguay. International Journal of Climatology, 37(12), 4261-4274.

Barreiro M, Díaz N. 2011. Land-atmosphere coupling in El Niño influence over South America. Atmospheric Science Letters, 12(4), 351-355.

Brito AS. 2011. El Niño and El Niño Modoki impacts on South American Rainfall. MSc dissertation. The University of New South Wales. Sydney. Australia.

Cai W, and Cowan T. 2009. La Niña Modoki impacts Australia autumn rainfall variability. Geophysical Research Letters, 36(12).

Cai W, Wang G, Dewitte B, Wu L, Santoso A, Takahashi K, Yan Y, Carréric A, and McPhaden MJ. 2018. Increased variability of eastern Pacific El Niño under greenhouse warming. Nature, 564(7735), 201.

Corbetta M. 1999. Sviluppo di una parametrizzazione semplificata dei fenemeni radiativi per modelli di circolazione generale atmosferica (Tesi di laurea, in Italian). University of Bologna (Italy), 112 pp.

Deardorff JW. 1972. Parameterization of the planetary boundary layer for use in general circulation models. Mon. Wea. Rev., 100, 93-106.

Grimm AM, Barros VR, and Doyle ME. 2000. Climate variability in southern South America associated with El Niño and La Niña events. Journal of climate, 13(1), 35-58.

Harshvardhan R, Davies D, Randall A, Corsetti TG. 1987: A fast radiation parameterization for atmospheric circulation models. J. Geophys. Res., 92, 1009-1016.

Harshvardhan, Randall DA, Corsetti TG, Dazlich DA. 1989. Earth radiation budget and cloudiness simulations with a general circulation model. /. Atmos. Set. 46, 1922-1942. 
Hartmann DL, 1994: Global physical climatology. Academic Press, San Diego, 411 pp.

Hill KJ, Taschetto AS, and England MH. 2009. South American rainfall impacts associated with inter-El Niño variations. Geophysical Research Letters, 36(19).

Hill KJ, Taschetto AS, and England MH. 2011. Sensitivity of South American summer rainfall to tropical Pacific Ocean SST anomalies. Geophysical Research Letters, 38(1).

Huang B, Banzon VF, Freeman E, Lawrimore J, Liu W, Peterson TC, Smith TM, Thorne PW, Woodruff SD, and Zhang HM. 2014. Extended Reconstructed Sea Surface Temperature version 4 (ERSST.v4): Part I. Upgrades and intercomparisons. Journal of Climate, 28, 911-930, doi:10.1175/JCLI-D-14-00006.1

Kanamitsu M, Ebisuzaki W, Woollen J, Yang SK, Hnilo JJ, Fiorino M, and Potter, GL. 2002. Ncepdoe amip-ii reanalysis (r-2). Bulletin of the American Meteorological Society, 83(11), 1631-1644.

King MP, Herceg-Bulić I, Bladé I, García-Serrano J, Keenlyside N, Kucharski F, ... and Sobolowski S. 2018. Importance of late fall ENSO teleconnection in the Euro-Atlantic sector. Bulletin of the American Meteorological Society, (2018).

Kucharski F, Molteni F, Bracco A. 2006. Decadal interactions between the western tropical Pacific and the North Atlantic Oscillation. Clim. Dyn. 26: 79-91.

Kucharski F, Bracco A, Yoo JH, Molteni F. 2007. Low-frequency variability of the Indian monsoonENSO relationship and the tropical Atlantic: The "weakening" of the 1980s and 1990s. Journal of Climate, 20(16), 4255-4266.

Larkin NK, and Harrison DE. 2005. Global seasonal temperature and precipitation anomalies during El Niño autumn and winter. Geophysical Research Letters, 32(16).

Li G, Ren B, Yang C, and Zheng J. 2010. Indices of El Niño and El Niño Modoki: An improved El Niño Modoki index. Advances in Atmospheric Sciences, 27(5), 1210-1220.

Li JL, Ko“ hler M, Farrara JD, Mechoso CR. 2002. The impact of stratocumulus cloud radiative properties on surface heat fluxes simulated with a general circulation model. Mon. Wea. Rev., 130, $1433-1441$. 
López-Parages J, Rodríguez-Fonseca B, and Terray L. 2015. A mechanism for the multidecadal modulation of ENSO teleconnection with Europe. Climate dynamics, 45(3-4), 867-880.

Losada T, Rodríguez-Fonseca B, Polo I, Janicot S, Gervois S, Chauvin F, Ruti P. 2010. Tropical response to the Atlantic Equatorial mode: AGCM multimodel approach. Climate Dynamics, 35(1), 45-52.

Ma HY, Ji X, Neelin JD, Mechoso CR. 2011. Mechanisms for precipitation variability of the eastern Brazil/SACZ convective margin. Journal of Climate, 24(13), 3445-3456.

Ma HY, Xiao H, Mechoso CR, Xue Y. 2013. Sensitivity of global tropical climate to land surface processes: Mean state and interannual variability. Journal of Climate, 26(5), 1818-1837.

Martín-Gómez V, and Barreiro M. 2015. Analysis of oceans' influence on spring time rainfall variability over Southeastern South America during the 20th century. International Journal of Climatology, 36(3), 1344-1358.

Mohino E, Rodríguez-Fonseca B, Losada T, Gervois S, Janicot S, Bader J, Ruti P, Chauvin F. 2011. Changes in the interannual SST-forced signals on West African rainfall. AGCM intercomparison. Climate Dynamics, 37(9-10), 1707-1725.

Molteni F. 2003. Atmospheric simulations using a GCM with simplified physical parameterizations. I: Model climatology and variability in multi-decadal experiments. Clim. Dyn. 20: 175-191.

Pan DM, Randall DM. 1998. A cumulus parameterization with a prognostic closure. Quarterly Journal of the Royal Meteorological Society, 124(547), 949-981.

Plumb RA. 1985. On the three-dimensional propagation of stationary waves. Journal of the Atmospheric Sciences. 42(3), 217-229.

Reason CJC, Rouault M. 2002. ENSO-like decadal variability and South African rainfall. Geophysical Research Letters 29: 1638, DOI: 10.1029/2002GL014663. 
Richter I, Mechoso CR, and Robertson AW. 2008. What determines the position and intensity of the South Atlantic anticyclone in austral winter?-An AGCM study. Journal of Climate, 21(2), 214-229.

Ropelewski CF, and Halpert MS. 1986: North American precipitation and temperature patterns associated with the El Niño Southern Oscillation (ENSO). Mon. Wea. Rev.,114, 2352-2362.

Saravanan R, Chang P. 2000. Interaction between tropical Atlantic variability and El Niño-Southern Oscillation. J. Clim. 13: 2177-2194.

Silva GAM, and Ambrizzi T. 2006. Inter-El Niño variability and its impact on the South American low-level jet east of the Andes during austral summer? two case studies. Advances in Geosciences, 6 , 283-287.

Silvestri GE. 2004. El Niño signal variability in the precipitation over southeastern South America during the austral summer. Geophys. Res. Lett. 31(18): L18206, doi: 10.1029/2004GL020590.

Suarez MJ, Arakawa A, Randall DA. 1983. The parameterization of the planetary boundary layer in the UCLA general circulation model: Formulation and results. Mon. Wea. Rev., 111, 2224-2243

Sulca J, Takahashi K, Espinoza JC, Vuille M, and Lavado-Casimiro W. 2018. Impacts of different ENSO flavors and tropical Pacific convection variability (ITCZ, SPCZ) on austral summer rainfall in South America, with a focus on Peru. International Journal of Climatology, 38(1), 420-435.

Sun D, Xue F, and Zhou T. 2013. Impacts of two types of El Niño on atmospheric circulation in the Southern Hemisphere. Advances in Atmospheric Sciences, 30(6), 1732-1742.

Tedeschi RG, Cavalcanti IF, and Grimm AM. 2013. Influences of two types of ENSO on South American precipitation. International Journal of Climatology, 33(6), 1382-1400.

Tedeschi RG, Grimm AM, and Cavalcanti IF. 2015. Influence of Central and East ENSO on extreme events of precipitation in South America during austral spring and summer. International Journal of Climatology, 35(8), 2045-2064.

Tiedke M. 1993. A comprehensive mass flux scheme for cumulus parameterization in large-scale models. Mon. Wea. Rev., 117, 1779-1800. 
Villafuerte MQ,,and Matsumoto J. 2015. Significant influences of global mean temperature and ENSO on extreme rainfall in Southeast Asia. Journal of Climate, 28(5), 1905-1919.

Weng H, Behera SK, Yamagata, T. 2009. Anomalous winter climate conditions in the Pacific rim during recent El Niño Modoki and El Niño events. Climate Dynamics, 32(5), 663-674.

Xiang B, Wang B, and Li T. 2013. A new paradigm for the predominance of standing central Pacific warming after the late 1990s. Climate Dynamics, 41(2), 327-340.

Xie P, and Arkin PA. 1997: Global precipitation: A 17-year monthly analysis based on gauge observations, satellite estimates, and numerical model outputs. Bull. Amer. Meteor. Soc., 78, 2539 2558.

Xue Y, Sellers PJ, Kinter JL, Shukla J. 1991. A simplified biosphere model for global climate studies. Journal of Climate, 4(3), 345-364.

Yuan Y, and Yang S. 2012. Impacts of different types of El Niño on the East Asian climate: Focus on ENSO cycles. Journal of Climate, 25(21), 7702-7722.

Zhang W, Li H, Stuecker MF, Jin FF, and Turner AG. 2016. A new understanding of El Niño's impact over East Asia: Dominance of the ENSO combination mode. Journal of Climate, 29(12), 4347-4359. 


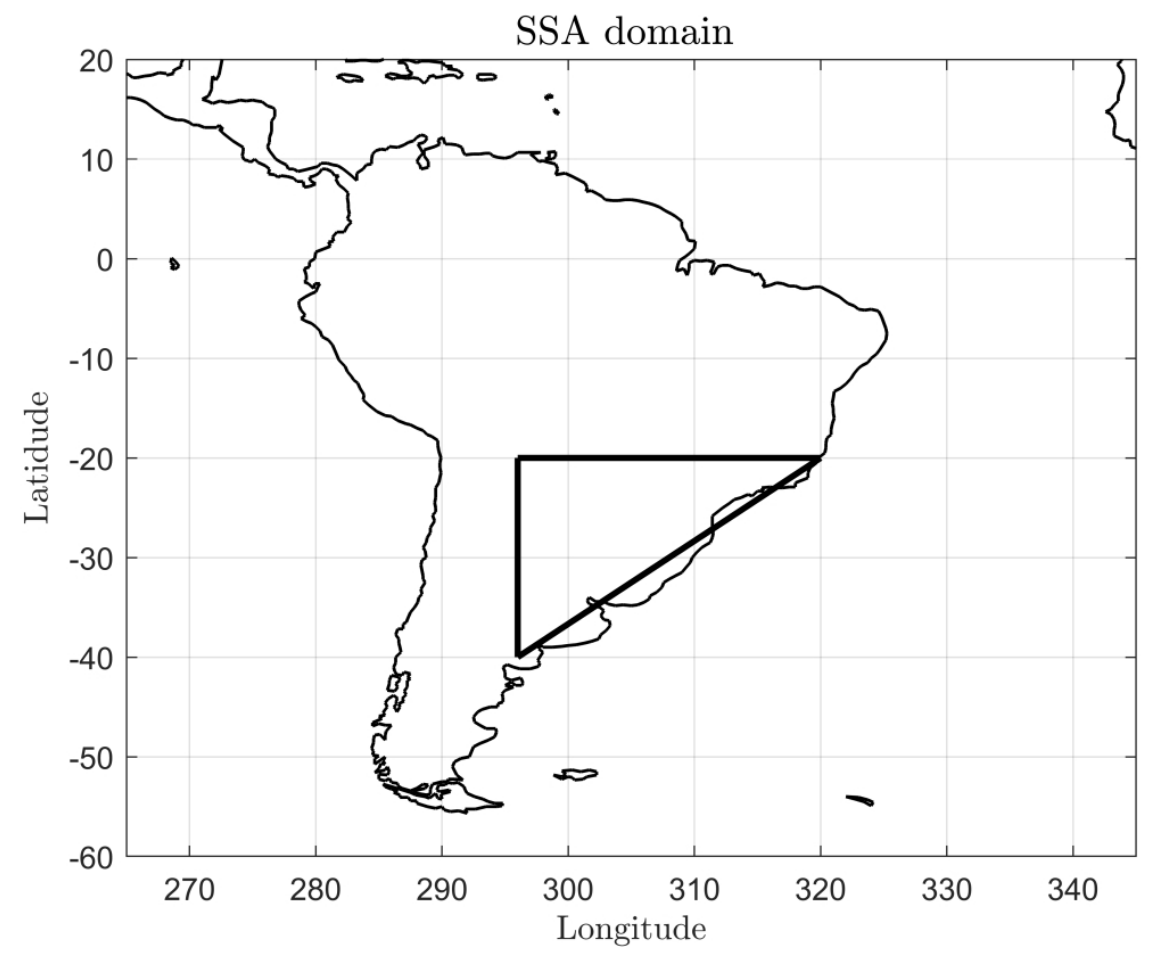

Figure 1. Subtropical South America (SSA) domain. $148 \times 111 \mathrm{~mm}(700 \times 700 \mathrm{DPI})$ 

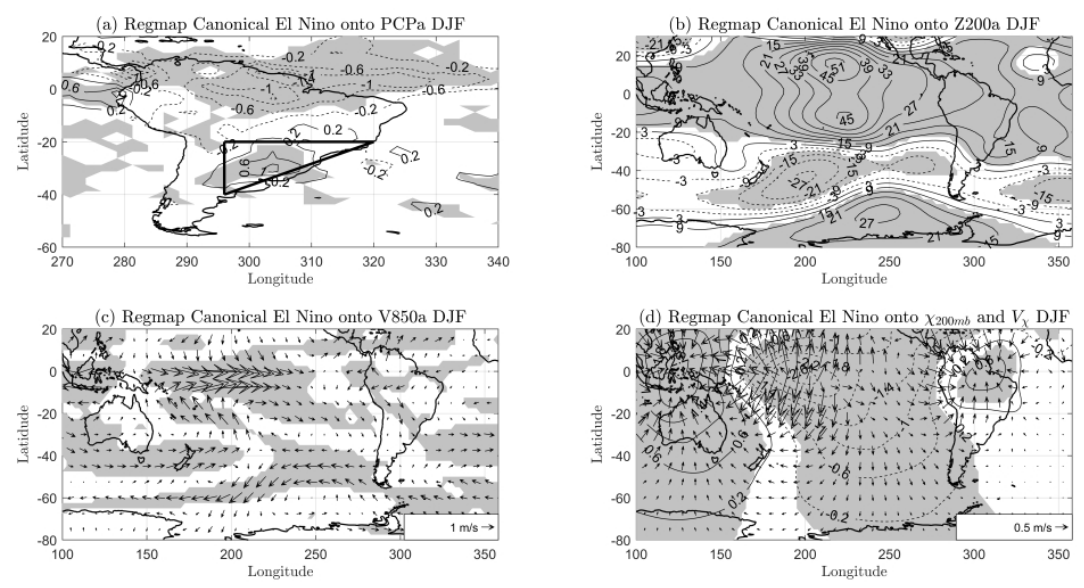

Figure 3. Regression maps of Canonical El Niño index onto: (a) PCP(mm/day) anomaly, (b) Z200 (m) anomaly, (c) V850hPa (m/s) anomaly $(\mathrm{m} / \mathrm{s})$ and $(\mathrm{d}) \times(\mathrm{m} 2 / \mathrm{s})$ and $\mathrm{VX}(\mathrm{m} / \mathrm{s})$ at $200 \mathrm{hPa}$ anomalies from reanalysis. $X$ values should be multiplied by $10^{\wedge} 6$. Shaded regions exceed the $90 \%$ level of confidence from one - tailed $\mathrm{t}$ - test.

$338 \times 160 \mathrm{~mm}(600 \times 600 \mathrm{DPI})$

This article is protected by copyright. All rights reserved. 

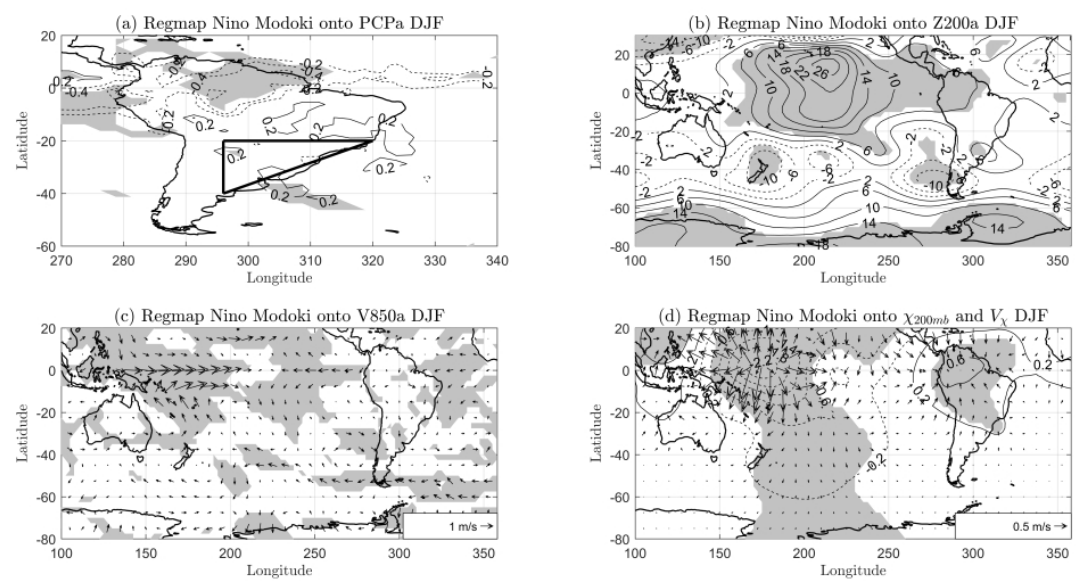

Figure 4. Regression maps of El Niño Modoki index onto: (a) PCP(mm/day) anomaly, (b) Z200 (m) anomaly, (c) V850hPa (m/s) anomaly $(\mathrm{m} / \mathrm{s})$ and $(\mathrm{d}) X(\mathrm{~m} 2 / \mathrm{s})$ and $V_{X}(\mathrm{~m} / \mathrm{s})$ at $200 \mathrm{hPa}$ anomalies from reanalysis. $X$ values should be multiplied by $10^{\wedge} 6$. Shaded regions exceed the $90 \%$ level of confidence from one - tailed $t$ - test.

$338 \times 160 \mathrm{~mm}(600 \times 600 \mathrm{DPI})$ 

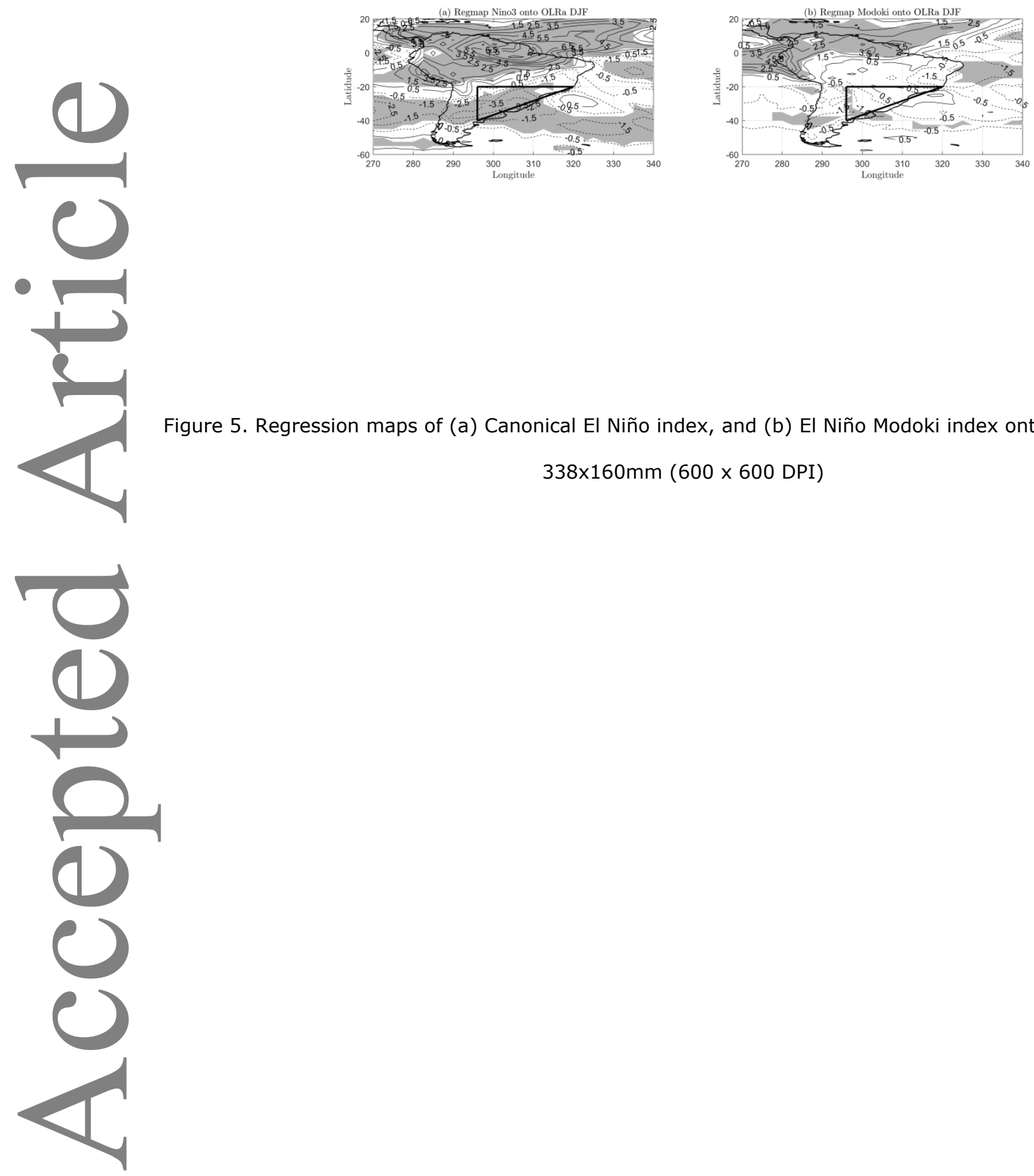

Figure 5. Regression maps of (a) Canonical El Niño index, and (b) El Niño Modoki index onto OLR anomalies. $338 \times 160 \mathrm{~mm}(600 \times 600 \mathrm{DPI})$ 

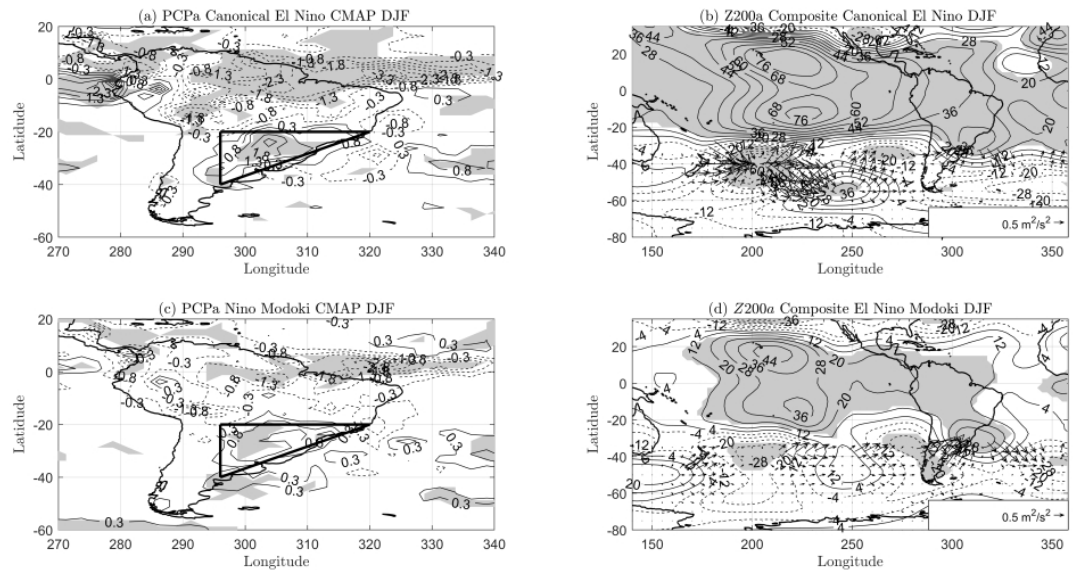

Figure 6. Composite maps for the strong Canonical El Niño events: (a) PCP anomalies (mm/day), (b) z200 anomalies (m). Composite maps for stronger El Niño Modoki events: (c) PCP anomalies (mm/day), (d) z200 anomalies $(\mathrm{m})$. Vectors over figures (b) and (d) represent the quasi - stationary wave flux (m2/s2). Triangle on Figures (a) and (c) represents the SSA region.

$338 \times 160 \mathrm{~mm}(600 \times 600 \mathrm{DPI})$

This article is protected by copyright. All rights reserved. 

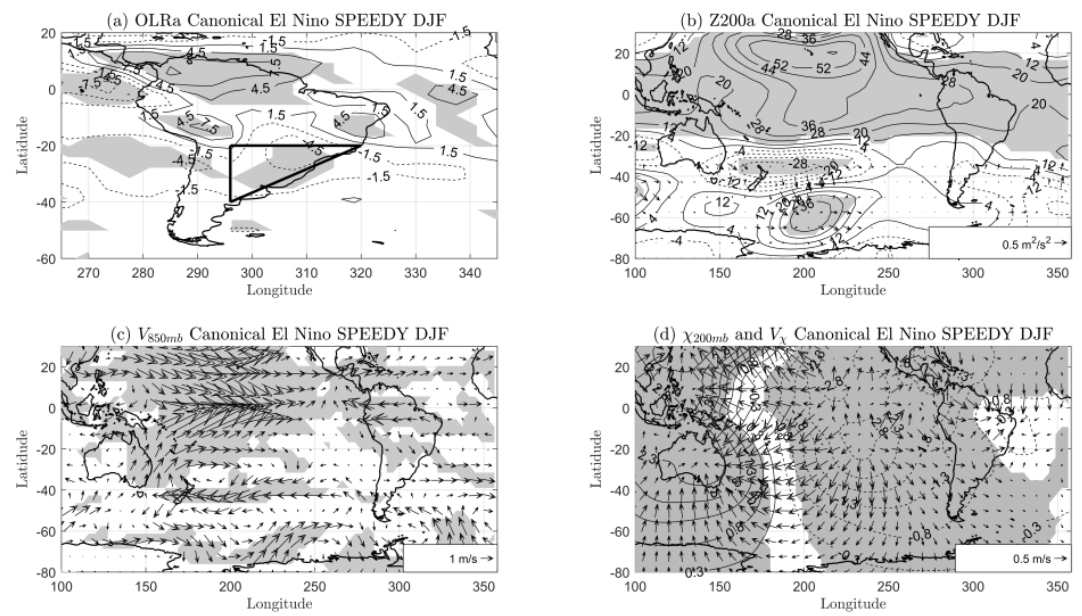

Figure 7. Composite maps for Canonical El Niño events using SPEEDY model. (a) OLRa (W/m2), (b) Z200a $(\mathrm{m}),(\mathrm{c}) \mathrm{V} 850 \mathrm{hPa}(\mathrm{m} / \mathrm{s})$ anomaly and $(\mathrm{d}) \mathrm{X}(\mathrm{m} 2 / \mathrm{s})$ and $\mathrm{VX}(\mathrm{m} / \mathrm{s})$ at $200 \mathrm{hPa}$ anomalies. Composites were computed as the average of the 11 Canonical El Niño simulations minus the ensemble mean of the 11 climatological simulations. $x$ should be multiplied by the factor $10^{\wedge} 6$. Shaded regions exceed the $90 \%$ level of confidence from one - tailed $t$ - test. Triangle on figure (a) represents SSA.

$338 \times 172 \mathrm{~mm}(600 \times 600 \mathrm{DPI})$ 

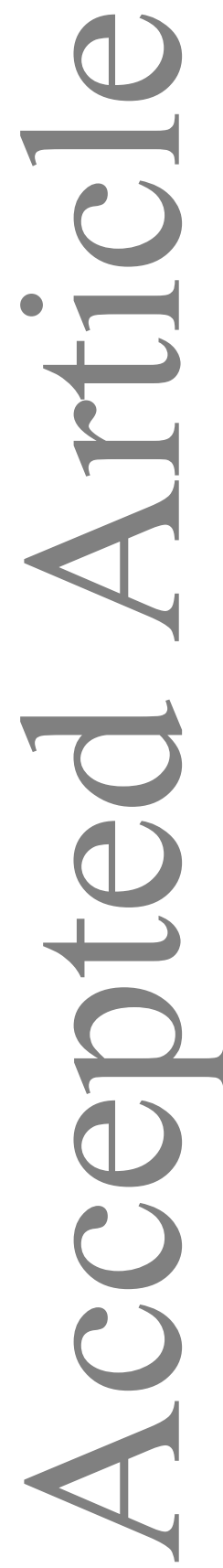
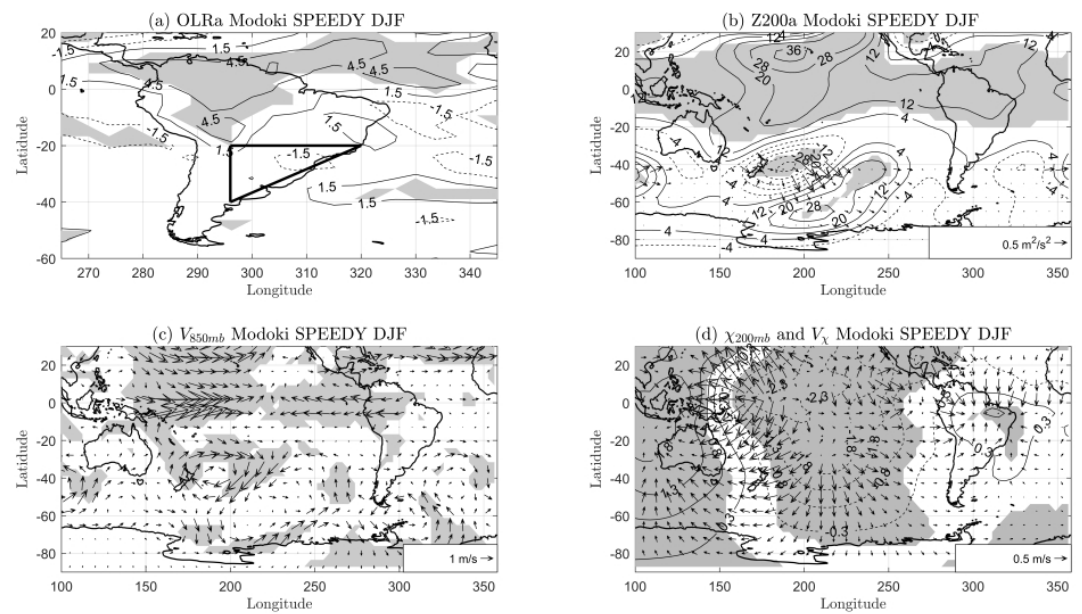

Figure 8. Composite maps for El Niño Modoki events using SPEEDY model. (a) OLRa (W/m2), (b) Z200a (m), (c) $V 850 \mathrm{hPa}(\mathrm{m} / \mathrm{s})$ anomaly and $(\mathrm{d}) X(\mathrm{~m} 2 / \mathrm{s})$ and $V_{X}(\mathrm{~m} / \mathrm{s})$ at $200 \mathrm{hPa}$ anomalies. Composites were computed as the average of the 11 Canonical El Niño simulations minus the ensemble mean of the 11 climatological simulations. $x$ should be multiplied by the factor $10^{\wedge} 6$. Shaded regions exceed the $90 \%$ level of confidence from one - tailed $t$ - test. Triangle on figure (a) represents SSA.

$338 \times 172 \mathrm{~mm}(600 \times 600 \mathrm{DPI})$ 

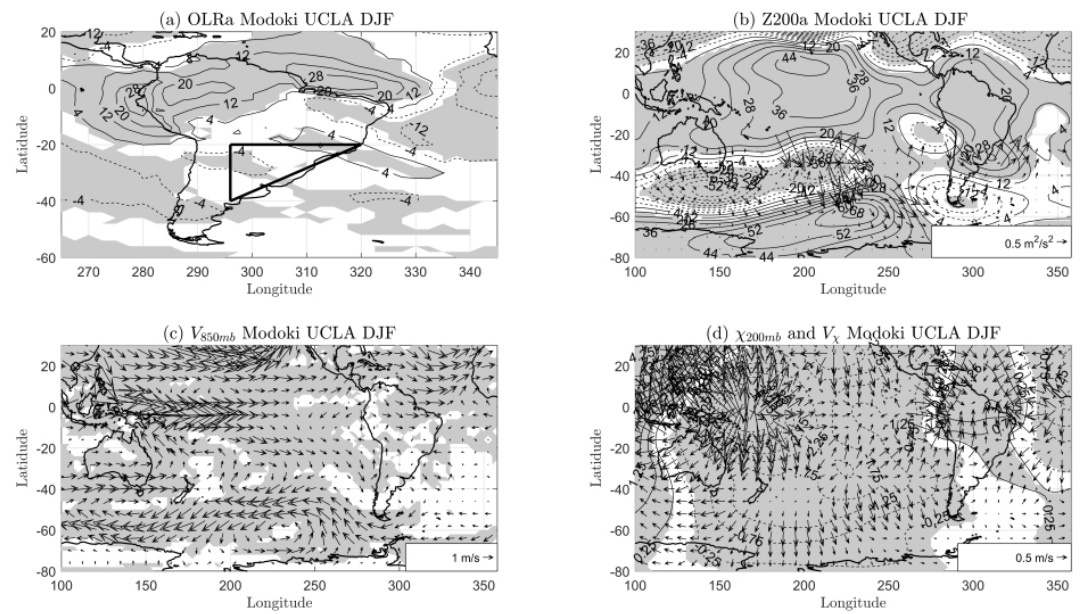

Figure 10. Composite maps for El Niño Modoki events using UCLA - AGCM model. (a) OLRa (W/m2), (b) Z200a (m), (c) V850hPa (m/s) anomaly and (d) X (m2/s)and VX $(\mathrm{m} / \mathrm{s})$ at $200 \mathrm{hPa}$ anomalies. Composites were computed as the average of the 11 Canonical El Niño simulations minus the ensemble mean of the 11 climatological simulations. $x$ should be multiplied by the factor $10^{\wedge} 6$. Shaded regions exceed the $90 \%$ level of confidence from one - tailed $t$ - test. Triangle on figure (a) represents SSA.

$338 \times 172 \mathrm{~mm}(600 \times 600 \mathrm{DPI})$ 

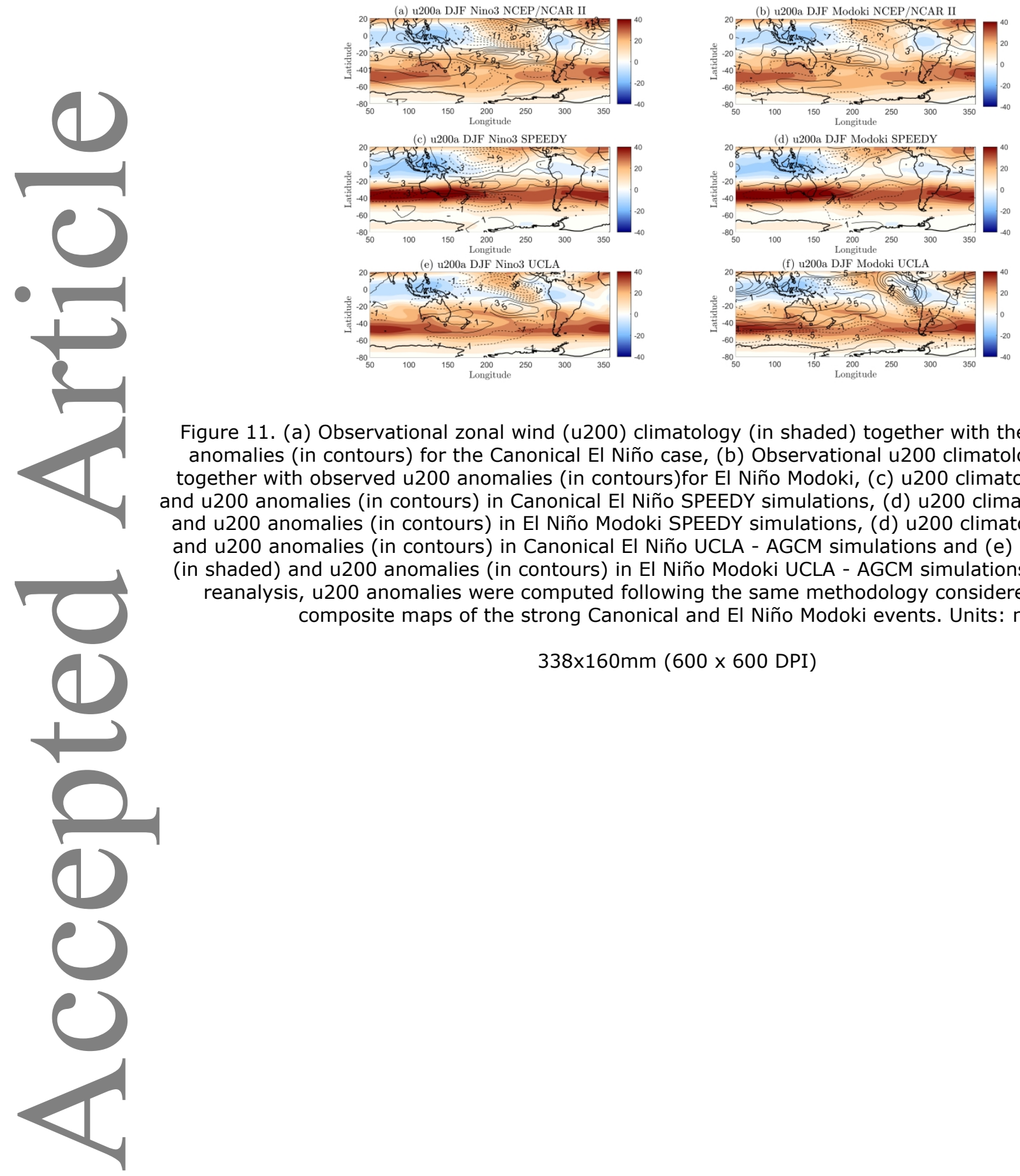

Figure 11. (a) Observational zonal wind (u200) climatology (in shaded) together with the observed u200 anomalies (in contours) for the Canonical El Niño case, (b) Observational u200 climatology (in shaded) together with observed u200 anomalies (in contours)for El Niño Modoki, (c) u200 climatology (in shaded) and u200 anomalies (in contours) in Canonical EI Niño SPEEDY simulations, (d) u200 climatology (in shaded) and u200 anomalies (in contours) in El Niño Modoki SPEEDY simulations, (d) u200 climatology (in shaded) and u200 anomalies (in contours) in Canonical El Niño UCLA - AGCM simulations and (e) u200 climatology (in shaded) and u200 anomalies (in contours) in El Niño Modoki UCLA - AGCM simulations. For the case of reanalysis, u200 anomalies were computed following the same methodology considered to compute composite maps of the strong Canonical and El Niño Modoki events. Units: m/s.

$$
338 \times 160 \mathrm{~mm}(600 \times 600 \mathrm{DPI})
$$



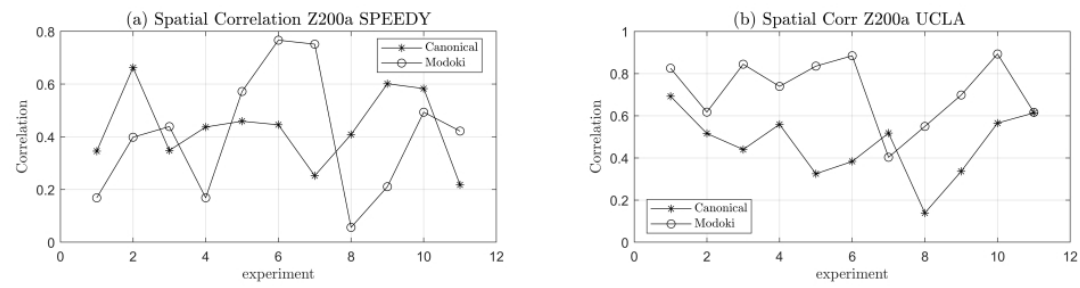

Figure 12. Spatial correlation between each one of the Z200 - ensemble members and the Z200 - ensemble mean. (a) SPEEDY, (b) UCLA - AGCM. Correlations were computed considering the Pacific + Atlantic sector over the Southern Hemisphere. Solid line with asterisks (circles) represent the case of Canonical El Niño (EI Niño Modoki).

$338 \times 160 \mathrm{~mm}(600 \times 600 \mathrm{DPI})$

This article is protected by copyright. All rights reserved. 


\begin{tabular}{|c|c|c|c|}
\hline Canonical El Niño & El Niño Modoki & \multicolumn{2}{|c|}{ Neutral } \\
\hline $1982 / 1983$ & $1991 / 1992$ & $1979 / 1980$ & $1992 / 1993$ \\
\hline $1986 / 1987$ & $1994 / 1995$ & $1980 / 1981$ & $1993 / 1994$ \\
\hline $1997 / 1998$ & $2002 / 2003$ & $1981 / 1982$ & $2001 / 2002$ \\
\hline $2006 / 2007$ & $2004 / 2005$ & $1983 / 1984$ & $2003 / 2004$ \\
\hline $2015 / 2016$ & $2009 / 2010$ & $1987 / 1988$ & $2012 / 2013$ \\
\hline-- & $2014 / 2015$ & $1989 / 1990$ & $2013 / 2014$ \\
\hline
\end{tabular}

Table 1. Strong Canonical El Niño, El Niño Modoki and neutral years during the period (19792016). The year 1997/1998 means December 1997 and January - February 1998. Gray shaded boxes satisfied the criterion to be classified as both, Canonical and El Niño Modoki events. However, they were classified as El Niño Modoki events attending to the spatial distribution of the SST anomalies. 